\title{
Pregnancy with previous caesarean section: an overview of adverse fetomaternal sequelae
}

\author{
Joyita Bhowmik, Amit Kyal*, Indrani Das, Vidhika Berwal, \\ Pijush Kanti Das, Partha Mukhopadhyay
}

Department of Obstetrics and Gynecology, Medical College, Kolkata, 88, College Street, West Bengal, India

Received: 23 February 2018

Accepted: 28 March 2018

\section{*Correspondence:}

Dr. Amit kyal,

E-mail: amitkyal@yahoo.com

Copyright: (C) the author(s), publisher and licensee Medip Academy. This is an open-access article distributed under the terms of the Creative Commons Attribution Non-Commercial License, which permits unrestricted non-commercial use, distribution, and reproduction in any medium, provided the original work is properly cited.

\begin{abstract}
Background: The Caesarean section epidemic is a reason for immediate concern and deserves serious international attention. The purpose of this study was to evaluate adverse maternal and fetal complications associated with pregnancies with history of previous caesarean section.

Methods: A cross-sectional, observational study carried out over a period of 1 year from $1^{\text {st }}$ June 2016 to $31^{\text {st }}$ July 2017 in Medical College Kolkata. 200 antenatal patients with previous history of 1 or more caesarean sections were included. In all cases thorough history, complete physical and obstetrical examination, routine and case specific investigations were carried out and patients were followed till delivery and for 7 days thereafter. All adverse maternal and fetal complications were noted.

Results: Out of 200 women, 30 candidates were tried for VBAC, of them 20 (66.66\%) had successful outcome. Most common antenatal complication was APH (5.5\%) due to placenta praevia followed by scar dehiscence. There were 12 cases $(6.66 \%)$ of PPH and 6 cases $(3.33 \%)$ of scar dehiscence in the study group. 3 cases required urgent hysterectomy due to placenta accreta. 42 out of 196 babies required management in SNCU immediately or later after birth.

Conclusions: Women with a prior cesarean are at increased risk for repeat cesarean section. Vigilance with respect to indication at primary cesarean delivery, proper counselling for trial of labor and proper antepartum and intrapartum monitoring of patients are key to reducing the cesarean section rates and maternal complications.
\end{abstract}

Keywords: Maternal morbidity, Repeat caesarean section, Scar rupture, Vaginal birth after caesarean section

\section{INTRODUCTION}

With the sky rocketing caesarean section rates an increasing number of women face the issue of mode of delivery in their current pregnancy. The Caesarean section epidemic is a reason for immediate concern and deserves serious international attention. ${ }^{1}$ The main concern in cases of pregnancy with scarred uterus is that it might end up in rupture, leading to severe maternal and perinatal morbidity and mortality. The presence of a CS scar affects the site of implantation and the distance between implantation site and the scar is related to the risk of spontaneous abortion, scar dehiscence and morbid adherent placenta. Apart from scar related complications there are other morbidities related to post caesarean deliveries like scar pregnancy, traumatic postpartum hemorrhage, dense abdominal adhesions, rectus sheath hematoma, UTI, cervical tear, adherent bladder and thinned lower uterine segment. In the management of patient with previous caesarean section, regular and intensive antenatal surveillance is required. Proper 
selection, appropriate timing and suitable methods of induction with close supervision by competent staff are necessary. $^{2}$

This study was carried out to assess the fetomaternal outcome in previous history of caesarean pregnancy so that we can implement better safety measures to avoid any maternal complications arising due to caesarean sections.

\section{METHODS}

It was a cross-sectional, observational institution-based study carried out over a period of 1 year from $1^{\text {st }}$ june2016 to $31^{\text {st }}$ july2017 in Department of Obstetrics and Gynaecology, Eden hospital, Medical College Kolkata. 200 antenatal patients with previous history of 1 or more caesarean sections were included after institutional ethical clearance and proper consent from the patients. All pregnant mother with history of previous one or more caesarean sections who were admitted under our unit were included. Patients with history of previous uterine surgeries(myomectomy/hysterotomy), malpresentation, multiple pregnancy, diagnosed IUGR, fetus with congenital anomaly and associated medical illness were excluded from the study.

In all cases thorough history, complete physical and obstetrical examination, routine and case specific investigations (blood investigations and USG) were carried out and patients were followed up till delivery and for 7 days thereafter. All adverse maternal and fetal complications were noted. The outcome measured for mothers were uterine rupture; hysterectomy; postpartum haemorrhage (PPH); postpartum infection; admission to intensive care unit (ICU); manual removal of placenta and maternal mortality. Fetal outcome measured were stillbirth, asphyxia; SNCU admission at birth and other complications.

\section{RESULTS}

In the present study, 200 obstetric patients with previous history of caesarean deliveries admitted under our unit were chosen. In all cases thorough history taking and clinical examination was done. They were followed up until they were discharged postpartum. Results thus obtained were analysed and expressed in tables.

Table 1: Age distributions of the patients $(n=200)$.

\begin{tabular}{|lll|}
\hline Age in years & No. of patients & Percentage (\%) \\
\hline$<20$ & 62 & 31 \\
\hline$>20-25$ & 94 & 47 \\
\hline$>25-30$ & 38 & 19 \\
\hline$>30-35$ & 2 & 1 \\
\hline$>35$ & 4 & 2 \\
\hline
\end{tabular}

The most frequent age group with previous history of caesarean section being admitted was between 20-25 years $(47 \%)$, followed by patients less than 20 years (31\%) between 18-40 years (Table1).

Table 2: Distribution of patients according to socioeconomic status $(n=200)$.

\begin{tabular}{|lll|}
\hline Status & No. of patients & Percentage $(\%)$ \\
\hline Low & 155 & 77.5 \\
\hline Middle & 45 & 22.5 \\
\hline Modified BG Prasad's classification for $\mathbf{2 0 1 3}$ \\
\hline $\begin{array}{l}\text { Socioeconomic standard } \\
\text { class }\end{array}$ & $\begin{array}{l}\text { Modified BG Prasad's } \\
\text { classification for 2013 }\end{array}$ \\
\hline 1 & Rs. 5156 and above \\
\hline 2 & Rs. 2578-51551 \\
\hline 3 & Rs. 1547-2577 \\
\hline 4 & Rs. 773-1546 \\
\hline 5 & Below Rs 773 \\
\hline
\end{tabular}

Socioeconomic standard of study population was assessed by modified BG Prasad's classification of socioeconomic standard of 2013 using per capita income in their family

Of the studied populations $77.5 \%$ belonged to low socioeconomic status and $22.5 \%$ were of middle socioeconomic status (Table 2).

Table 3: Antenatal check-ups.

\begin{tabular}{|ll|}
\hline Cases & Percentage \\
\hline Booked & 30 \\
\hline Unbooked & 70 \\
\hline
\end{tabular}

Only $30 \%$ of patients had regular antenatal check-ups and were booked cases at the referring and the present hospital (Table 3).

Table 4: Case distribution according to inter delivery interval $(n=200)$.

\begin{tabular}{|lll|}
\hline Months & No. of cases & Percentage \\
\hline 6-12 months & 15 & 7.5 \\
\hline$>12$ months & 185 & 92.5 \\
\hline
\end{tabular}

It was seen that 15 cases $(7.5 \%)$ conceived within 1 year of previous caesarean section and in the remaining 185 patients $(92.5 \%)$ the pregnancy interval was $>1$ year with respect to previous delivery (Table 4$)$.

Table 5: Mode of delivery $(n=200)$.

\begin{tabular}{|lll|}
\hline $\begin{array}{l}\text { Mode of delivery } \\
\text { Elective repeat caesarean } \\
\text { delivery }\end{array}$ & 30 & 15 \\
\hline $\begin{array}{l}\text { Emergency caesarean } \\
\text { section those were not } \\
\text { fulfilling the criteria of } \\
\text { trial of labour }\end{array}$ & 150 & 75 \\
\hline Vaginal birth & 20 & 10 \\
\hline
\end{tabular}

In the present study 30 patients were tried for VBAC as they fulfilled the criteria and gave the required consent. 
The success rate of VBAC was $66.66 \%$ i.e. 20 patients delivered vaginally, and 10 patients required emergency CS because of fetal distress, cord prolapse, non-progress of labour and suspicion of scar dehisence. Out of the remaining patients 130 underwent repeat elective LSCS and 150 required emergency $\mathrm{CS}$ for various causes (Table $5)$.

Table 6: Antenatal maternal complications on/after $\operatorname{admission}(n=200)$.

\begin{tabular}{|lll|}
\hline $\begin{array}{l}\text { Maternal } \\
\text { complications }\end{array}$ & No. of patients & Percentage \\
\hline Placenta praevia & 11 & 5.5 \\
\hline Scar dehiscence & 6 & 3 \\
\hline Shock & 6 & 3 \\
\hline Scar rupture & 4 & 2 \\
\hline Death & 2 & 1 \\
\hline
\end{tabular}

As evidenced by the Table 6, the most common antenatal complication was APH (5.5\%) due to placenta praevia followed by scar dehiscence and shock either following scar rupture or APH (3\% each). There were 2 maternal deaths $(1 \%)$ due to shock as a result of placenta accrete.

Table 7: Difficulties encountered during caesarean section.

\begin{tabular}{|lll|}
\hline $\begin{array}{l}\text { Difficulties during repeat } \\
\text { caesarean section }\end{array}$ & $\begin{array}{l}\text { No. of cases } \\
(\mathrm{n}=180)\end{array}$ & $\%$ \\
\hline $\begin{array}{l}\text { Difficulty in opening abdomen } \\
\text { Difficulty in separation of } \\
\text { bladder }\end{array}$ & 74 & 41.11 \\
\hline $\begin{array}{l}\text { Difficulties due to placenta } \\
\text { praevia/accrete }\end{array}$ & 11 & 13.33 \\
\hline No difficulties & 71 & 6.11 \\
\hline
\end{tabular}

As apparent from Table 7, difficulty in opening the abdomen was encountered in 74 patients $(41.11 \%)$ because of adhesions between uterus and undersurface of rectus sheath. Difficulty in separation of bladder was seen in $24(13.33 \%)$ patients. There were 11 cases of placenta praevia out of which 3 were placenta accreta (Table 7).

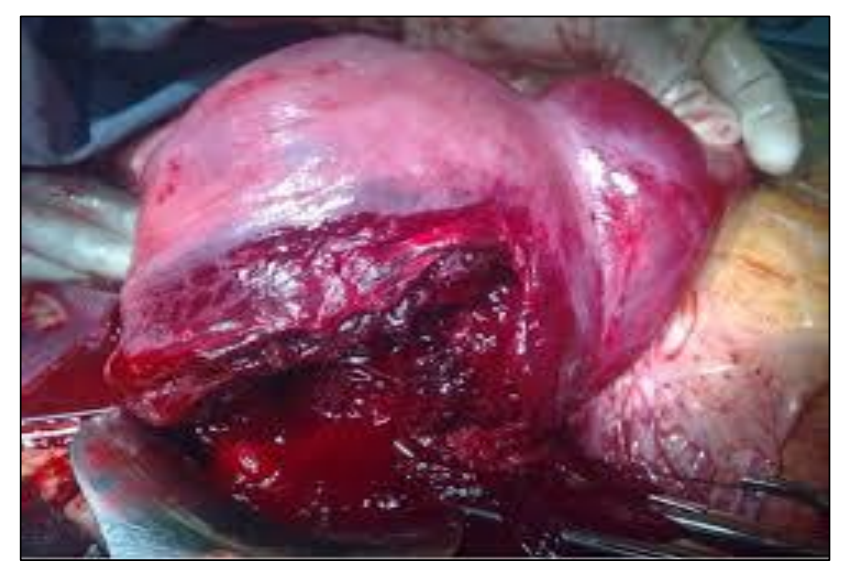

Figure 1: Scar rupture seen during laparotomy.
Table 8: Uterine scar status during caesarean section $(n=180)$.

\begin{tabular}{|lll|}
\hline Condition of scar & No. of cases & Percentage \\
\hline Healthy scar & 170 & 94.44 \\
\hline Dehiscence of scar & 6 & 3.33 \\
\hline Rupture of scar & 4 & 2.22 \\
\hline
\end{tabular}

Scar dehiscence was seen intra-operatively in 6 patients $(3.33 \%)$ and 4 cases had scar rupture $(2.22 \%)$ which were clear cut and repair was done followed by bilateral tubal ligation (Table 8) (Figure 1 and 2).

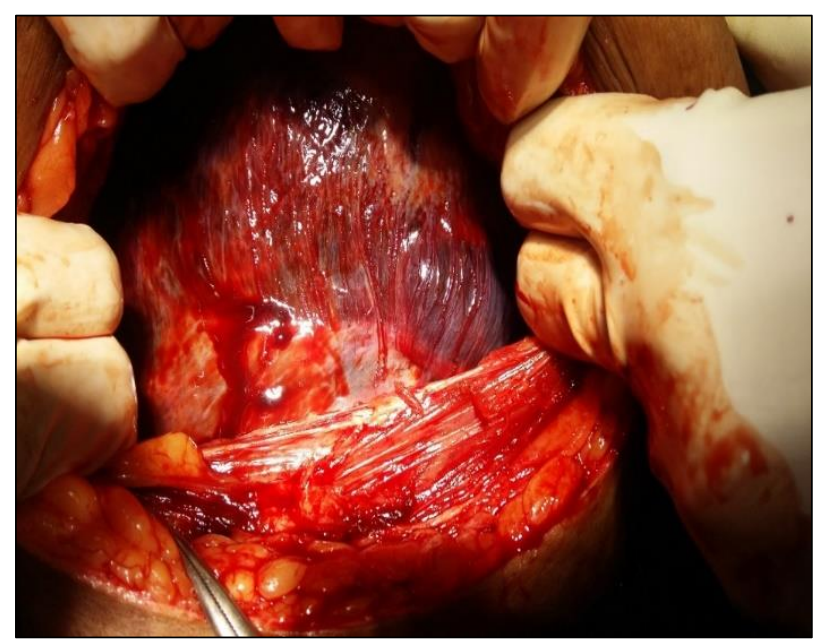

Figure 2: Scar dehiscence seen during caesarean section.

The most common problem faced during caesarean section was PPH $(6.66 \%)$ followed by wound extension $(3.33 \%)$. 3 cases required urgent hysterectomy due to placenta accreta. Bowel and bladder injuries occurred in 2 cases each $(1.1 \%)$ (Table 9$)$.

Table 9: Intraoperative complications.

\begin{tabular}{|lll|}
\hline Complications & No. $(\mathrm{n}=\mathbf{1 8 0})$ & Percentage \\
\hline Pph & 12 & 6.66 \\
\hline Wound extension & 6 & 3.33 \\
\hline Hysterectomy & 3 & 1.66 \\
\hline Bladder injury & 2 & 1.1 \\
\hline Gut injury & 2 & 1.1 \\
\hline
\end{tabular}

Out of 180 patients in whom LSCS was performed 48 cases $(26.66 \%)$ had postoperative complications. Puerperal pyrexia in 17 cases due to UTI and wound infection and 15 patients had gaping of the LSCS wound. Blood transfusion was required in 12 cases. Hospital stay ranged from 10-21 days and 2 patients required CCU admission due to hypovolemic shock.

Of a total of 200 births, 4 stillbirths were seen which was due to uterine rupture. 96 out of 196 deliveries (48.97\%) were at term whereas 100 out of 196 deliveries $(51.01 \%)$ were preterm. 
Table 10: Distribution of neonates according to APGAR score at birth.

\begin{tabular}{|lll|}
\hline Apgar score & No. of babies $\mathbf{N}=196$ & Percentage \\
\hline$<3$ & 0 & 0 \\
\hline $3-4$ & 2 & 1.02 \\
\hline $5-6$ & 5 & 2.55 \\
\hline $7-8$ & 18 & 9.5 \\
\hline$>8$ & 171 & 87.5 \\
\hline
\end{tabular}

42 out of 196 babies required management in SNCU immediately or later after birth. Out of 196 babies 7 $(3.57 \%)$ had very low APGAR score at birth because of scar dehiscence and APH and were admitted in SNCU (Table 10).

\section{DISCUSSION}

There is a widespread public and professional concern about the increasing proportion of births by caesarean section worldwide. ${ }^{3}$ The Caesarean section epidemic is a reason for immediate concern and deserves serious international attention. The introduction of lower segment caesarean section gave a good and strong scar to the uterus, to hold and safely deliver a subsequent pregnancy. It is now safe to say that "once a caesarean section, always a hospital delivery". ${ }^{4}$ Incidence of rupture uterus varies from $0.3 / 1000$ to $7 / 1000$ deliveries in India accounting for $5 \%$ to $10 \%$ of all maternal deaths. ${ }^{5}$

In the present study, total 200 cases were included with one or more previous caesarean section, 30 cases were taken directly for elective caesarean section, 30 cases were given trial of labour and remaining 150 cases underwent emergency caesarean section without undergoing trial of labour. Out of 30 cases of TOL, 20 $(66.66 \%)$ were delivered vaginally and remaining 10 $(33.33 \%)$ cases had failed trial of labour and required emergency caesarean section. Our results were comparable to other studies of Bhat BPR et al, Pramod Kumar et al. ${ }^{6,7}$

In the present study it was seen that 15 cases $(7.5 \%)$ conceived within 1 year of previous caesarean section and 185 cases $(92.5 \%)$ conceived after 1 year of previous caesarean section. Huang et al had earlier concluded in their study that inter-delivery interval of less than 19 months were associated with a decreased rate of VBAC success in those who had induction but not in those who went into spontaneous labour. ${ }^{8}$ Shipp et al reported an increased rate of uterine rupture during a trial of labour in VBAC patients with interdelivery interval of less than 18 months. $^{9}$

About $85.5 \%$ antepartum patients were uneventful in our study. The most common antenatal complications were APH due to placenta praevia $(5.5 \%)$ followed by scar dehiscence and shock either following scar rupture or APH (3\% each). Maternal death was found to be $1 \%$ because of shock due to placenta accreta. Similarly, a study done by Nahar K, et al in around half (48\%) of the cases antepartum period was uneventful. Another $16 \%$ cases had some complications related with previous surgeries like placenta praevia, scar tenderness and chronic abdominal pain. ${ }^{10}$

Difficulty in opening the abdomen due to adhesions was encountered in $54(30 \%)$ of the patients. Adhesions between the omentum, peritoneum and bladder were seen in 20 cases $(11.11 \%)$. Difficulty in separation of the bladder in was seen in $24(13.33 \%)$ of the patients. There were 11 cases of placenta praevia, out of which 3 were placenta accreta. Same findings were seen in another study done by Jinturkar A et al where difficulty in opening the abdomen due to adhesions was encountered in 52 patients $(22.12 \%)$ and adhesions between the omentum, peritoneum and bladder was seen in 19 patients $(8.08 \%)$. Difficulty in separation of the bladder in was seen in 23 patients $(9.79 \%)^{11}$ Parikh et al found excessive adhesions in $36 \%$ of the patients for LSCS in his study. ${ }^{12}$

During the present study, scar dehiscence and scar rupture were seen in $6(3.33 \%)$ and 4 cases $(2.22 \%)$ respectively. Similar study by Anagha A, et al showed scar dehiscence in $2.74 \%$ cases. ${ }^{11}$ The incidence of scar rupture is quite high in our study as compared to the normal incidence rate i.e. $0.2-0.9 \%$ in single low transverse incision and $0.9-1.8 \%$ in multiple low transverse incision. ${ }^{13}$

From the current study, the most common problem faced during caesarean section was PPH $(6.66 \%)$ followed by wound extension $(3.33 \%)$. In contrast to our findings, study done by Goel SS et al, showed PPH in $48.55 \%$ cases which was quite high. ${ }^{2}$

Out of 200 cases 11 had placenta praevia out of which 3 patients $(1.5 \%)$ were placenta accreta and underwent total hysterectomy. The incidence of placenta accreta in the present study is quite low as compared to the known incidence rate of accreta i.e. $3 \%$ for unscarred uterus, $11 \%$ for previous one LSCS and $40 \%$ for previous 2 LSCS. In a Network study, by Silver and associates, they reported an incidence of placenta praevia of 1.3 percent for those with only one prior cesarean delivery. ${ }^{14}$

Out of 180 patients in whom LSCS was performed 48 cases $(26.66 \%)$ had postoperative complications. Puerperal pyrexia in 17 cases $(8.55 \%)$ either due to UTI or wound infection and 15 patients $(7.5 \%)$ had LSCS wound gaping. Hospital stay ranged from 10-21 days and 2 patients required CCU admission due to hypovolemic shock. The rate of complication is significantly less in this study in comparison to other two studies done by Chowdhury et al and Asaduzzaman. ${ }^{15,16}$ Similar results were found in other study by Anagha A, et al where complications occurred in $25.1 \%$ cases. ${ }^{11}$ Of a total of 200 births in our study, 3 stillbirths were seen $(1.5 \%)$ which was due to rupture uterus. 7 babies $(3.57 \%)$ had 
APGAR score less than 7 at birth because of scar dehiscence and APH and were admitted in SNCU. Ismail $\mathrm{S}$, et al found 23 cases $(4.9 \%)$ had fresh still birth and 7 perinatal deaths $(1.5 \%)$. APGAR score was less than five at five minutes in $31(6.6 \%)$ and $138(29.4 \%)$ of the neonates admitted to nursery. ${ }^{17}$

In the present study, 96 out of 196 deliveries i.e. $48.97 \%$ were at term whereas 100 out of 196 deliveries (51.01\%) were preterm. Another study done by Nahar K, et al found majority (91\%) of the cases were admitted with term, only $9 \%$ were with preterm. ${ }^{10}$

\section{CONCLUSION}

Due to rise in Caesarean section rate as a primary mode of delivery in past few years, the number of pregnancies with previous Caesarean section has also increased. Rising trend of caesarean section has been associated with fetomaternal complications. Vigilance with respect to indication at primary cesarean delivery, proper counseling for trial of labor and proper antepartum and intrapartum monitoring of patients are key to reducing the cesarean section rates. If the incidence of primary caesarean section rates is reduced, the complications associated with repeat caesarean section can be decreased. Substantial reduction in the caesarean rate can be achieved safely and efficiently by encouraging the trial of labour in women with a single previous caesarean delivery.

Funding: No funding sources

Conflict of interest: None declared

Ethical approval: The study was approved by the Institutional Ethics Committee

\section{REFERENCES}

1. Mukherjee SN. Rising caesarean section rate. J Obstet Gynecol India. 2006;56:298-300.

2. Goel SS, Tiwari M, Hariharan C, Shrivastava DS. Outcome of post caesarean pregnancy and comparison of maternal and foetal outcome following vaginal birth versus repeat caesarean section in a rural hospital. Int $\mathbf{J}$ Reprod Contracept Obstet Gynecol. 2013;2(1):16-22.

3. Parliamentary Office of Science and Technology. Caesarean sections. Postnote. 2002;184:1-4.

4. Dodd J, Crowther CA. VBAC: a survey of practice in Australia and New Zealand. Aust N Z J Obstet Gynaecol. 2003;43:226-31.

5. Latika SA. 10-year analysis of uterine rupture at a teaching institution. J Obstet Gynecol India. 2006;56(6):502-6.
6. Bhat BPR, Savant R, Kamath A. Outcome of a post caesarean pregnancy in a tertiary centre of a developing country. J Clin Diagn Res. 2010;3:20059.

7. Kumar P, Shivkumar PV, Jaiswal A, Kumar N, Saharan K. Subjective assessment of LSCS scar site for vaginal birth after caesarean trial and outcome in MGIMS, Sewagram, Wardha, India. Int J Biol Med Res. 2012;3:1825-9.

8. Huang WH, Nakashima DK, Rumney PJ, Keegan KA Jr, Chan K. Interdelivery interval and the success of vaginal birth after cesarean delivery. Obstet Gynecol. 2002;99:41-4.

9. Shipp TD, Zelop CM, Repke JT, Cohen A, Lieberman E. Interdelivery interval and risk of symptomatic uterine rupture. Obstet Gynecol. 2001;97:175-7.

10. Nahar K, Akhter L, Chowdhury SB. Outcome of pregnancy with history of previous cesarean section. Orion Med J. 2008;31:588-90.

11. Anagha A, Jinturkar D, Dipti. Study of obstetric and fetal outcome of post caesarean section pregnancy at tertiary care center. Int J Recent Trends Sci Tech. 2014;10(3):530-7.

12. Parikh V. Management of patients with previous caesarean section. J Obstet Gynaecol India. 1964;14:327.

13. Dutta DC. Textbook of obstetrics including perinatology and contraception, $9^{\text {th }}$ ed. Jaypee, New Delhi; 2018:394

14. Silver RM, Landon MB, Rouse DJ. Maternal morbidity associated with multiple repeat cesarean deliveries. Obstet Gynecol. 2006;107:1226.

15. Chowdhury SB, Newaz R, Begum A, Dewan F. Indications and complications of cesarean section: a study of 1083 cases. Bangladesh J Obstet Gynecol. 1994;9:1-7.

16. Asaduzzaman K. A study on factors and outcome of cesarean section among the patients admitted in a tertiary care hospital, Dhaka, Bangladesh College of Physicians and Surgeons. 1996.

17. Umbeli $\mathrm{T}$, Ismail $\mathrm{S}$, Kunna $\mathrm{A}$, Elmahgoub A. Maternal and neonatal complications associated with caesarean section in the second stage of labour at Omdurman maternity hospital during 2012-2013. Merit Res J Med Medical Sci. 2014;2(10):225-8.

Cite this article as: Bhowmik J, Kyal A, Das I, Berwal V, Das PK, Mukhopadhyay P. Pregnancy with previous caesarean section: an overview of adverse fetomaternal sequelae. Int J Reprod Contracept Obstet Gynecol 2018;7:1817-21. 